\title{
Diabetes mellitus as etiological factor of hearing loss
}

Clícia Adriana S. Maia ${ }^{1}$, Carlos Alberto H. de Campos ${ }^{2}$

Key words: hearing loss, diabetic angiopathy, diabetes mellitus, retinopathy, neuropathy.

\section{Summary}

$\mathbf{P}$ atients with diabetes mellitus often show symptoms such as dizziness, tinnitus, and hearing impairment. In general, hearing loss is sensorineural, which is sometimes confused with presbycusis, mainly because it develops in patients older than 40 years of age. Angiopathy and neuropathy caused by diabetes mellitus have been considered important factors for the vestibular-cochlear disorders found in these patients. However, there is controversy regarding the etiopathogenesis of hearing loss, as some researchers support that it develops due to neuropathy, others say it is due to angiopathy, or even a combination of both. Yet, some researchers believe diabetes mellitus and hearing loss are part of a genetic syndrome. We have conducted an extensive bibliographic review to determine whether there is cause-effect relationship between diabetes mellitus and hearing loss. We were able to verify that, despite the large number of studies performed, there is still a great deal of controversy, and new approaches are being studied, for example in the field of genetics, which shows that new paths can be followed to reach a conclusion on this issue.

${ }^{1}$ Otorhinolaryngologist; Supporting Professor, Medical School, Universidade Estadual Santa Cruz; Post-graduation in Otorhinolaryngology under course, Faculdade de Ciências Médicas da Santa Casa de São Paulo. ${ }^{2}$ Joint Professor, Head of the Department of Otorhinolaryngology, Faculdade de Ciências Médicas da Santa Casa de São Paulo. Address correspondence to: Clicia Adriana Santos Maia - Av. Firmino Alves, 60 sala 205 Ed. Módulo Center Itabuna BA $45600-185$. Tel (55 73) 613-0424/613-0218/91913870 - E-mail: clicia.adriana@terra.com.br Article submited on May 26, 2004. Article accepted on March 21, 2005. 


\section{INTRODUCTION}

The most frequent causes of vestibular and auditory abnormalities are attributed to dysfunctions in the metabolism of carbohydrates, thyroid affections, supra adrenal, and other different metabolic disorders. Among glucose metabolism disorders, diabetes mellitus is the affection most commonly related with auditory disorders ${ }^{1}$.

Diabetes mellitus is a genetically determined metabolic disorder associated with absolute or relative impairment of insulin and in complete clinical manifestation is characterized by metabolic affections, vascular and neuropathic complications. The main objective of treating patients with diabetes is the prevention of chronic complications because the disease is not curable but only controllable. In Brazil, the incidence of chronic complications of diabetes is quite high. It is estimated that there are five million subjects with diabetes and half of them are not aware of the diagnosis. A large number of subjects, especially children and adolescents, have diagnosis of diabetes made in face of complications, especially infections ${ }^{2}$.

One of the morphological aspects more constant in diabetes mellitus is diffuse thickness of basal membrane, which may also happen with vascular endothelium, and it is named diabetic microangiopathy. It is more evident in skin capillaries, skeletal muscles, retina, renal glomeruli, and renal medulla. Its pathogenesis is still obscure, but it is clearly associated with hyperglycemia. Other morphological affections refer to impairment of both motor and sensorial nerves of lower limbs, characterized as Schwann cell lesions, degeneration of myelin and axon damage. The cause of neuropathy is still very controversial, and it may be related with diffuse microangiopathy that would affect nourishment of peripheral nerves ${ }^{3}$.

Neuropathy and angiopathy are common affections in diabetes mellitus. Angiopathy has been observed in small arteries and skin capillaries, muscle, kidney, retina and peripheral nerves. The factors that may cause neuropathy are metabolic disorders (glucose metabolism, lipid metabolism defects and vitamins). Some researchers referred to the fact that vascular affections in interfascicular or intrafascicular branches of vasonbervorum contribute to neuropathy. Atherosclerosis, however, very common in diabetes mellitus, can also contribute to neuropathy, owing to interference in rate of nutrient transfer ${ }^{4}$.

Angiopathy may occur both in direct way, interfering with supply to the cochlea by reducing transport through the thickened walls of capillaries, and indirectly by the reduction of flow in vascular pathways, or still, because of secondary degeneration of 8 th cranial nerve 5 .

Concerning diabetes mellitus, there are different opinions about the pathological affections caused in the auditory system.

According to Nageris et al., the association between hearing loss and diabetes mellitus has been debated since it was first reported by Jordao in $1857^{6}$.

In the literature, there are many different types of hearing loss found in diabetic patients. One of them is progressive, gradual bilateral sensorineural loss, affecting especially high frequencies and the elderly. It would be similar to presbyacusis, but with more severe losses than those expected by aging ${ }^{5-8}$. Conversely, there are authors that report the possibility of having early sensorineural loss ${ }^{7}$ and others that reported hearing loss in low and medium frequencies ${ }^{9,10}$. Some studies described diabetes as the possible cause of unilateral sudden loss ${ }^{4,10,11}$, but other authors did not find the same association ${ }^{12}$.

As to incidence of hearing loss in patients with diabetes mellitus, we observed that there is no consensus in the literature either, ranging from zero to $93 \%{ }^{6}$.

In view of the reported data, we decided to perform a literature review to check whether there is really a hearing loss inherit to diabetes mellitus and to which factors it is related.

\section{LITERATURE REVIEW}

\section{A) Diabetic angiopathy: structural and ultrastructural aspects}

Diabetic angiopathy has been characterized by endothelial proliferation, accumulation of glucoprotein in the intima and thickness of basal membrane of capillaries and small blood vessels. We can also observe fibrotic thickness of the wall and narrowing of internal auditory artery lumen. We confirmed accumulation of positive PAS substance (periodical Schiff acid) on the artery wall, as well as on the modiolus vessels and vascular stria capillaries ${ }^{4}$.

\section{A1) Animal lab experimental studies}

The effects of diabetes in the inner ear can be studied in experimental model by using diabetogenic drugs (alloxan or streptozocin), in genetically modified animals with diabetes (such as Sabra line rats) by means of total or subtotal pancreatectomy and still by extraction of anterior hypophysis.

$\operatorname{Costa}^{13}$ (1967) used alloxan to induce diabetes in rats to assess diabetic angiopathy. They found optical microscopy with increase in thickness of vessel walls of modiolus, more marked six months after the induction of diabetes. We did not observe structural changes to Corti's organ, in ganglionar cells or in nervous fibers.

Smith et al. ${ }^{14}$ (1995) confirmed that diabetic microangiopathy occurred in the inner ear of rats induced with the use of streptozocin. In the studied group, there was quantitative documentation by electron transmission microscopy of the increase in thickness of capillary basal membrane of vascular stria, which was not observed in the control group. 
Raynor et al..$^{15}$ (1995) also used streptozocin to induce diabetes mellitus and observed that loss of outer hair cells was greater in diabetic rats that were simultaneously exposed to noise.

The use of alloxan or intraperitoneal streptozocin to induce diabetes in experimental models has been contested because it did not reflect the real physiological mechanism of diabetes in human beings because it has genetic origin. Thus, Nageris et al. ${ }^{6}$ (1998) used rats of Sabra line who have the tendency to presenting intolerance to glucose when submitted to 21 days of rich carbohydrate diet. They concluded that if there is sensorineural loss associated with diabetes mellitus, its pathogenesis does not involve damage to hair cells or stria vascularis.

Triana et al. $^{16}$ (1991), using rat line (SHR/N-cp Spontaneous hypertensive rats/ corpulent), who stated that this is the only genetic model for non-insulin-dependent diabetes mellitus, observed significant loss of outer hair cells in animals that were simultaneously obese and diabetic, when compared to the control group. However, a similar experiment was conducted with other authors using the same animal mode and they concluded that diabetes alone did not cause significant thickness of basal membrane, but in combination with obesity and exposure to noise they presented thickness, which was considered significant ${ }^{17}$.

\section{A2) Anatomic pathological study in humans}

Willianson \& Killo $^{18}$ (1977), in a review study mentioned that basal membrane of the capillary is formed by collagen proteins that are common in the connective tissue and also in scarring tissues, given that synthesis of these substances increase in response to a variety of stimuli and damage. They stated that thickness of basal membrane of the capillary associated with diabetes is considered a proliferative response of capillary cells to damage. They reported that this thickness is attributed to repetitive episodes of death of endothelial cells and their regeneration (with retention of necrotic endothelial cells on the basal membrane and beginning of new layers of the same membrane by regeneration). They concluded that a great variety of in vivo and in vitro studies are also consistent with this hypothesis, suggesting that synthesis of basal membrane and tissue renovation are increased in diabetes and that degradation of basal membrane is reduced or damaged.

Jorgensen \& Buch9 (1961), in a study with temporal bones of 32 diabetic subjects of all age ranges, showed that the main affections are shown in preparations of stria vascularis blood vessels when stained by PAS periodical Schiff acid - a staining method that clearly defines the basal membrane, mesangial matrix and hyalinosis. In this study, we found massive deposits of PAS on the capillary walls of stria vascularis, which were 10 to 20 times thicker than the usual, and had homogeneous or lamellar structure. Abnormalities were similar to those seen in atherosclerosis, but more marked, occurring only in the stria vascularis. These authors observed degeneration in other parts of the labyrinth, but they corresponded to findings in temporal bones of nondiabetic people of the same age range. The study confirmed that angiopathy is not generalized, and it is preferably directed to some capillary systems of inner ear, such as for example, stria vascularis. However, based on these investigation, the authors state that they can not come to conclusions about the chemical nature of the precipitate, because many substances are stained by this method. They reported that affections are typical to diabetes and not specific for the disease, observing that atherosclerosis is peripherally reduced, whereas diabetic angiopathy increases its intensity in the region of small vessels.

Costa $^{13}$ (1967), in a study conducted with temporal bone of six subjects that were used in their comparative study previously reported, have also detected positive PAS material on the wall of stria vascularis capillaries and modiolus, in addition to thickness of basal membrane in both sites.

Makishima and Tanaka ${ }^{4}$ (1971) used the temporal bone of four subjects and also found impregnation by periodical Schiff acid on thickness of capitally walls of stria vascularis and modiolus, which was considered responsible for narrowing of vessel lumen, more intensively affected by inner auditory artery.

After these initial data on diabetes mellitus and hearing, most researchers agreed that primary lesions are angiopathic $4,10,14$.

\section{B) Diabetic neuropatby: structural and audiological aspects B1) Clinical pathology studies in humans}

Makishima \& Tanaka ${ }^{4}$ (1971) described atrophy of spiral ganglion neurons and demyelization of the 8th cranial nerve in four diabetic subjects. They showed demyelization is also the initial lesion of peripheral nerves of diabetes extremity and that there are indications of abnormalities of myelin metabolism that may have significant importance in pathogenesis of diabetic neuropathy. Using optical microscopy, we observed demyelization of auditory nerve by defferentation of myelin sheath with small affections to axon and fibrosis of perineurum, severe atrophy of spiral ganglion with loss of cell of basal turn and medium turn of the cochlea, in addition to decrease in number of nervous fibers on the spiral lamina. Other findings were: reduction of number of ganglionar cells of ventral and dorsal cochlear nuclei, small loss of ganglionar cells of superior olivary nucleus, inferior colliculus and medial geniculate body. In auditory centers of both temporal bone, they did not detect any specific affections directly attributed to diabetes mellitus.

\section{B2) Audiological study in human}

There are other authors that believe that neuropathy is the primary lesion of hearing loss, arguing that positive 
PAS material found in the vessel wall is very nonspecific, found also in other diseases. They conducted an audiometric study in 20 patients with diabetic peripheral neuropathy using the control of 32 patients with diabetes mellitus. They observed that the thresholds of peripheral neuropathy subjects were also worse than the control group, in all frequencies. And also that patients aged over 60 years were worse than both groups. Hearing loss found by them was normally sensorineural, progressive and more intense when over the age of 60 years 7 .

\section{C) Correlation between angiopathy and/or diabetic neuropathy and bearing loss}

Table 1 presented the studies that referred to finding a relation between diabetes mellitus and hearing loss and Table 2 presents studies that did not find a correlation between them.

\section{D) Correlation between genetic affection, diabetes mellitus and hearing loss}

It is known that hearing loss can also have its origin from genetic mutations, which can be congenital or acquired, occur in nuclear genes and mitochondria and present syndromic or non-syndromic episodes. DNA mitochondrial mutations are transmitted by maternal line, but there may be spontaneous mutations. As to physiopathogenesis of hearing loss, there are still many issues and theories ${ }^{19}$. Yamasoba et $\mathrm{a}^{20}$ (1996) presented the following theory: mitochondria 1 DNA affection $\rightarrow$ alteration in microchondril protein synthesis $\rightarrow$ alteration in oxiphative phosphorilation $\rightarrow$ reduction in the formation of ATP $\rightarrow$ alteration of ionic pumps $\rightarrow$ alterations in potassium, sodium and calcium $\rightarrow$ cell death.

In 1989, a specific genealogical tree was studied by Lemkes et al. ${ }^{21}$, in which nine children with diabetes mellitus also showed hearing loss.

Authors have observed a coinciding loss of variable severity in each diabetic patients. When the third-generation line was considered, they detected diabetes and hearing loss present only in children of affected mothers. This observation has strongly suggested that heritage is exclusively maternal, which is a particular characteristics of diseases associated with mitochondrial DNA mutation.

Newkirk et al. ${ }^{22}$ (1997) reported in a prospective study prevalence of diabetes mellitus and maternal inherited deafness in the population of diabetic patients at Newcastle Hospital. They reported that this association was a new subtype of diabetes and that it resulted from substitution of adenine for guanine at position 3243 of mitochondrial gene tRNA ${ }^{\text {Leu(uur) }}$ They also pointed out that this syndrome was originally identified as a cause of MELAS syndrome (myopathy, encephalopathy, lactic acidosis and repetitive episodes of cerebral vascular accident) and that sensorineural hearing loss was an additional symptom in about $70 \%$ of the cases.
In some cases, the same mutation may cause different phenotypes such as in the case of gene tRNA ${ }^{\text {leu }}$, a substitution of nucleotide adenine for guanine in locus 3243 , which may cause three different phenotypes: progressive chronic external ophthalmoplegia, diabetes, maternaloriginated deafness and MELAS syndrome. Clinically, diabetes mellitus and maternal inherited deafness are characterized by insulin-dependent diabetes, which can be non-insulin dependent at first, but normally evolves to it because the mitochondrial affection modifies insulin secretion by the pancreas; patients are thin and less than 40 years of age and hearing loss is normally sensorineural progressive ${ }^{19}$

Fowler et al. ${ }^{23}$ (1999) described Diadmoad syndrome or Wolfram syndrome also as a consequent mutation of mitochondrial DNA, characterized by diabetes insipidus and mellitus, optical atrophy and sensorineural hearing loss starting at childhood.

\section{DISCUSSION}

As presented in the literature review, there is not enough evidence to solidly define diabetes mellitus as a cause of hearing loss. There is no consensus on any aspect of this topic, either audiologically or histopathologically. Clinical experience, in many studies, showed direct correlation between hearing loss and diabetes, as reported in Table 1. However, there are other studies with more subjects and better designed that did not identify this association (Table 2).

Affection of blood vessels that irrigate the inner ear and affections that occur in stria vascularis of diabetic patients are unquestionable facts confirmed by different authors that believe in the correlation between hearing loss and diabetes, and these affections are strong evidences that diabetes may cause hearing loss ${ }^{10,13-15}$. However, there are others that do not believe in this association ${ }^{24}$.

Some studies indicate that decrease in hearing acuity, similarly to the one presented in presbyacusis, is greater than what is expected for the age in elderly and diabetic patients $8,10,12,22,24$. According to them, it is more likely that we can associated factors that would lead to hearing loss, such as consequence of vascular abnormalities caused by diabetes mellitus.

Up to 1960 , there were 3 theories about the pathogenesis of hearing loss caused by diabetes mellitus: neuropathy, angiopathy and association of both. Currently, there are significant reasons to believe that the angiopathy found in diabetic patients contributes to greater evidences of hearing loss. In favor of this hypothesis we can rely on histopathological findings of microvascular lesions of the inner ear, such as thickness of basal membrane of stria vascularis capillaries, as well as the fact that diffuse vascular affections caused by diabetes mellitus are well known ${ }^{4,13-15,25}$. 
Table 1. List of studies that found correlation between diabetes mellitus and hearing loss.

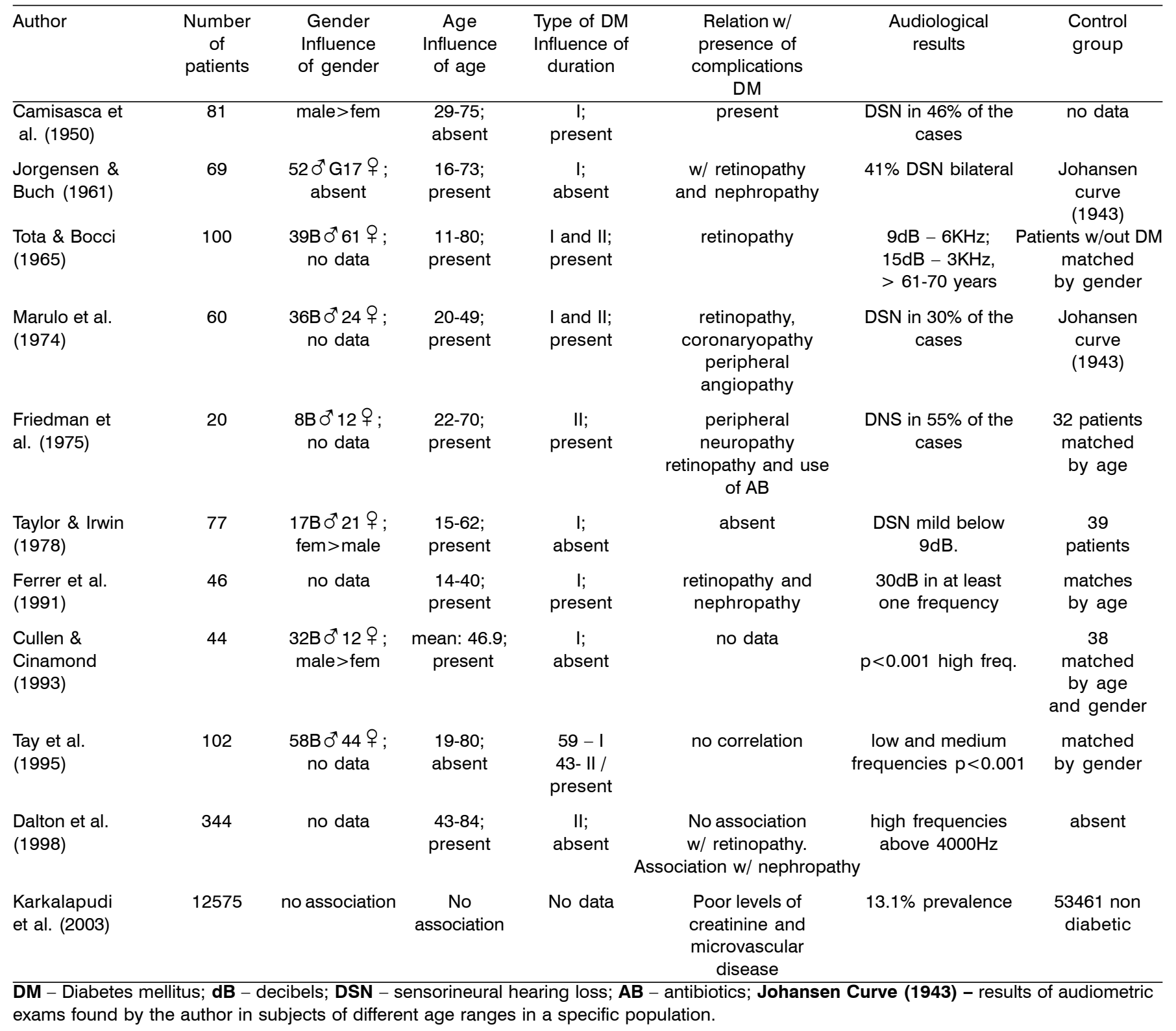

It is known that the main difficulty to conduct inner ear study is related with difficulty to access histological assessment, especially in human beings. Moreover, the steps to preparation of material can also have artifacts, provoking misinterpretations. The localization of inner ear circulation makes it difficult to study homeostasis, as well as the consequences of metabolic disorders. Other factors that can induce misinterpretation of statistical data are use of different populations for comparison purposes, lack of good control group, need to conduct longitudinal studies (owing to the fact that in transversal studies many times it is not possible to know if diabetes mellitus precedes hearing loss or vice-versa). Other important aspect is size of studied group and the huge universe of variables such as other diseases, use of drugs, noise exposure, genetic affections. It is possible that these are the reasons for discrepancy in results detected among similar studies conducted by different authors.

Finally, we observed growing interest in hearing loss caused by genetic affections, many of them related to mitochondrial DNA mutations. They correspond to $0.5 \%$ to $1 \%$ of all genetically-based hearing losses, which may be associated with syndromic presentations. One of the syndrome presentations is diabetes mellitus associated with 
Table 2. Studies that do not find correlation between diabetes mellitus and hearing loss.

\begin{tabular}{|c|c|c|c|c|c|c|c|}
\hline Author & $\begin{array}{c}\text { Number } \\
\text { of } \\
\text { patients }\end{array}$ & $\begin{array}{l}\text { Gender } \\
\text { Influence } \\
\text { of gender }\end{array}$ & $\begin{array}{c}\text { Age } \\
\text { Influence } \\
\text { of age }\end{array}$ & $\begin{array}{l}\text { Type of DM } \\
\text { Influence of } \\
\text { duration }\end{array}$ & $\begin{array}{c}\text { Relation w/ } \\
\text { presence of } \\
\text { complications DM }\end{array}$ & $\begin{array}{l}\text { Affected trequencies } \\
\text { loss in } d B\end{array}$ & $\begin{array}{l}\text { Control } \\
\text { group }\end{array}$ \\
\hline $\begin{array}{l}\text { Profazio \& } \\
\text { Barraveli } \\
(1959)\end{array}$ & 40 & no data & $\begin{array}{c}9-70 ; \\
\text { present }\end{array}$ & I; present & $\begin{array}{l}\text { Neuropathy } \\
\text { retinopathy and } \\
\text { use of } A B\end{array}$ & $\begin{array}{l}\text { DSN in } 55 \% \text { of the } \\
\text { cases }>44 \text { years }\end{array}$ & $\begin{array}{c}\text { Johansen } \\
\text { curve } \\
(1943)\end{array}$ \\
\hline $\begin{array}{l}\text { Strauss et } \\
\text { al. (1982) }\end{array}$ & 660 & $\begin{array}{l}\text { I-59\% ठ } \\
\text { II-30\% ठ } \\
\text { III-35\% ठ } \\
\text { no data }\end{array}$ & $\begin{array}{l}\text { I-mean: 35: } \\
\text { II e III- } \\
\text { mean: 65; } \\
\text { present }\end{array}$ & $\begin{array}{l}\text { I e II; } \\
\text { absent }\end{array}$ & $\begin{array}{c}\text { Other factors: } \\
\text { hypertension and } \\
\text { noise } \\
\text { exposure }\end{array}$ & $\begin{array}{c}\text { significant } \\
\text { abnormalities were } \\
\text { not found }\end{array}$ & $\begin{array}{c}\text { non- } \\
\text { diabetic } \\
\text { population }\end{array}$ \\
\hline Miller et al. (1983) & 33 & $\begin{array}{c}18 \mathrm{~B} \& / 15 \text { ㅇ } \\
\text { no data }\end{array}$ & $\begin{array}{l}\text { 22-72; } \\
\text { present }\end{array}$ & I; absent & $\begin{array}{l}\text { Other factors: } \\
\text { noise exposure }\end{array}$ & $\begin{array}{c}\text { significant } \\
\text { abnormalities } \\
\text { were not found }\end{array}$ & 209 \\
\hline $\begin{array}{l}\text { Axellson \& } \\
\text { Fagerberg } \\
(1968)\end{array}$ & 99 & $\begin{array}{c}\text { 59B\&/40 우 } \\
\text { absent }\end{array}$ & $\begin{array}{l}16-59 ; \\
\text { present }\end{array}$ & I; absent & $\begin{array}{c}\text { no } \\
\text { correlation }\end{array}$ & $\begin{array}{c}\text { significant } \\
\text { abnormalities were } \\
\text { not found }\end{array}$ & $\begin{array}{c}\text { Non- } \\
\text { diabetic } \\
\text { population }\end{array}$ \\
\hline
\end{tabular}

DM - Diabetes mellitus; dB - decibels; DSN - sensorineural hearing loss; AB - antibiotics; Johansen Curve (1943) - results of audiometric exams found by the author in subjects of different age ranges in a specific population.

maternal-inherited hearing loss, amounting to $1.5 \%$ of all cases of diabetes in Japan and The Netherlands ${ }^{19}$.

The investigation of genetic causes has been the answer to many questions and disagreeing results.

\section{CLOSING REMARKS}

In view of current knowledge, there is evidence that diabetes mellitus may cause hearing loss, but we can not state that there is clear cause-effect correlation. It is known that a series of variants may favor the association between both diseases, but it is necessary to conduct more careful studies to define the true role of these factors. As seen before, diabetes mellitus and hearing loss can be dependent components, or even components of a genetic syndrome and not dependent one on the other.

According to the analyzed studies, we can conclude that many questions will be answered by multicenter longitudinal studies with large populations and strict inclusion and exclusion criteria.

\section{REFERENCES}

1. Albernaz PLM. Doenças metabólicas da orelha interna. RBM Otorrinolaringologia 1995; 1: 18-22.

2. Chacra AR. Diabetes mellitus. IN: Prado FC, Ramos JÁ, Borges DR, Rothschild HA, eds. Artes Médicas. Tratado de Atualização Terapêutica. 20aed. São Paulo: Câmara Publicadora do Livro; 2001. p.375-89.

3. Robbins SL, Cotran RS, Kumar V. Pathologic Basis of disease (3rd ed.) Philadelphia: W.B. Sauders Co.; 1991. p.982-3.
4. Makishima K, Tanaka AK. Pathological changes of the inner ear and central auditory pathway in diabetes. Ann Otol Rhinol laringol 1971; 80(2): 218-28.

5. Taylor IG, Irwin J. Some audiological aspects of diabetes mellitus. J Laringol Otol 1978; 92(2): 99-113.

6. Nageris B, Hadar T, Feinmesser M, Elidan J. Cochlear histopathogic analysis in diabetic rats. The American Journal of Otology 1998; 19: 63-5.

7. Friedman SA., Schulman RH, Weiss S. Hearing and diabetic neuropathy. Arch Intern Med 1975; 135: 573-6.

8. Miller JJ, Beck L, Davis A, Jones DE, Thomas AB. Hearing loss in patients with diabetic retinopathy. Am J Otolaryngol 1983; 4(5): 342-8.

9. Tay HL, Ray N, Ohri R, Fronntko NJ. Diabetes mellitus and hearing loss. Clin Otolaryngol 1995; 20: 130-4.

10. Jorgensen MB, Buch NH. Studies on inner-ear and cranial nerves in diabetes. Acta Otolaringol. (Stockh.) 1961; 107: 179-82.

11. Camisasca L. L'esame dell'apparato cochleo-vestibulare nel diabete mellito. G Sci Med 1950; 5: 45-9.

12. Dalton DS, Klein R, Klein BEK, Moss SE, Cruickshanks KJ. Association of NIDDM and hearing loss; Diabetes Care 1998; 21(9): 1540-4.

13. Costa OA. Inner ear pathology in experimental diabetes. The Laryngoscope 1967; LXXVII: 68-75.

14. Smith TL, Raynor E, Prazma J, Buenting JE, Pillsbury HC. Insulinodependent diabetic microangiopathy in the inner ear. J. Laringol Otol 1995; 105: 236-40.

15. Raynor EM, Carrasco VN, Prazma J, Pillsbury HC. An assessment of cochlear hair - cell loss in insulin - dependent diabetes mellitus diabetic and noise-exposed rats. Arch Otolaryngol Head and Neck Surg 1995; 121: 452-6.

16. Triana RJ, Suits GW, Garrison S, Prazma J, Brechtelsbauer B, Michaelis OE, Pillsburg HC. Inner ear damage secondary to diabetes mellitus. Arch Otolaryngol Head and Neck Surg 1991; 117: 635-40.

17. Mcquen CT, Baxter A, Smith TL, Raynor E, Yoon SM, Prazma J, Pillsburg HC. Non-insulin-dependent diabetic microangiopathy in the inner ear. The Journal of Laryngology and Otology 1999; 113: 13-8. 
18. Williamson JR, Killo C. Capillary basement membrane disease in diabetes mellitus. Diabetes 1977; 26: 65.

19. Kakarlapudi V, Sawyer R, Staecker H. The Effect of Diabetes on Sensorioneural Hearing Loss. Otology \& Neurotology 2003; 24(3): 382-6.

20. Yamasoba T, Yoshimoto O, Tsukuda K, Nakamura M, Kaga K. Auditory findings in patients with maternally inherit diabete transfer RNAleu(uur) gene. Laryngoscope 1996; 106: 49-53.

21. Lemkes HHPJ, Vijlder M, Struyvnberg P, Kamp JJP, Frolich. Maternal inherited diabetes-deafness of the young. A new mitocondrial syndrome. Diabetologia 1989; 32(7): 509A.

22. Newkirk JE, Taylor RW, Howell N, Bindoff LA,Chinnery PF, Alberti K, Turnnbuill DM, Walker M. Maternally inherited diabetes and deafness: prevalence in a hospital diabetic population. Diabetic med 1997; 14(6): 457-60.

23. Fowler PD, Jones NS. Diabetes and hearing loss. Clin Otolaryngol 1999; 24(1): 3-8.

24. Axellson A, Fagerberg SE. Auditory function in diabetics. Acta Otolaryngol. 1968; 66: 49-64.

25. Marulo T. Perceptive hypoacusias in diabetes mellitus. Rev Laryngol Otol Rhinol 1975; 95(5) Supl. 6: 253-71.
26. España AR., Birrun O, Lorente J, Trassera J. Hearing and diabetes, ORL J Otorhinolaringol Relat Spec 1995; 57(6): 325-7.

27. Jáuregui RK, Domingues RB, Ibarra AO, Gonzales BD. Ver Invest Clin 1998; 50(2): 137-8

28. Carvalho MFP, Ribeiro FAQ. As deficiências auditivas relacionadas às alterações do DNA mitocondrial. Rev Bras Otorrinolaringol 2002; 68(2): 268-75.

29. Cullen JR, Cinnamond MJ. Hearing loss in diabetics. The journal of Laryngology and Otology 1993; 107: 179-82.

30. Tota G, Bocci G. Audiometric examinations in diabetic retinopathy. Riv Oto-neuro-oftal 1965; 491-508.

31. Ferrer JP, Birrun O, Lorent J, Conget JI, España R, Esmaltjs E, Gomis R. Auditory function in young patients with type 1 diabetes mellitus. Diabetes Res Clin Pract 1991; 11(1): 17-22.

32. Profazio A, Barravelli P. La funzione auditiva nel diabete. Otorinolaring Italiana 1959; 28(2): 103-11.

33. Strauss P, Schneider K, Terriuolo V, Sanches B. Laringol Rhinol. Inner ear and diabetes mellitus studies on 660 patients. Otol 1982; 61(6): 331-8 